\title{
Biochemical and hematological biomarkers of reproductive failure in bottlenose dolphins Tursiops truncatus
}

\author{
Ashley Barratclough ${ }^{1, *}$, Forrest M. Gomez ${ }^{1}$, Jeanine S. Morey ${ }^{1}$, \\ Jennifer M. Meegan ${ }^{1}$, Celeste Parry ${ }^{1}$, Lori Schwacke ${ }^{1}$, Eric D. Jensen ${ }^{2}$, \\ Cynthia R. Smith ${ }^{1}$
}

${ }^{1}$ National Marine Mammal Foundation, 2240 Shelter Island Drive, Suite 200, San Diego, CA 92106, USA

${ }^{2}$ US Navy Marine Mammal Program, 53560 Hull Street, San Diego, CA 92152, USA

\begin{abstract}
The physiological demands of pregnancy inevitably result in alterations in both biochemical and hematological parameters as fetal development occurs. The shifts observed in successful pregnancy in bottlenose dolphins Tursiops truncatus to support both fetal physiological needs and maternal basal requirements have been established according to each trimester. Detecting aberrations in blood-based biomarkers could help facilitate diagnosis of gestational abnormalities, improve our understanding of factors influencing reproductive outcomes and aid in prediction of reproductive failure. This study retrospectively analyzed 263 blood samples from 15 bottlenose dolphins in 21 failed pregnancies over 28 yr (1989-2017). Most samples remained within normal pregnancy reference ranges; however, significant shifts were observed between trimesters. Hematological alterations, compared to successful pregnancy reference ranges from previously published data, were consistent across failed pregnancies and included an increased prevalence of elevated $2^{\text {nd }}$ and $3^{\text {rd }}$ trimester neutrophils, elevated $2^{\text {nd }}$ trimester monocytes and decreased $3^{\text {rd }}$ trimester eosinophils. In addition, low hematocrit and low red blood cells were more prevalent in the $2^{\text {nd }}$ trimester. Biochemical shifts included an increased prevalence of elevated creatine phosphokinase in the $3^{\text {rd }}$ trimester outside of the normal reference ranges. Across failed pregnancies, calcium and iron were decreased in the $3^{\text {rd }}$ trimester. Significantly decreased progesterone in the $3^{\text {rd }}$ trimester was a negative prognostic indicator of pregnancy outcome with decreasing $3^{\text {rd }}$ trimester progesterone associated with failed pregnancy. This study demonstrates the use of blood-based biomarkers as possible predictors of pregnancy outcome in bottlenose dolphins.
\end{abstract}

KEY WORDS: Dolphin $\cdot$ Pregnancy $\cdot$ Failure $\cdot$ Blood $\cdot$ Biochemistry $\cdot$ Hematology $\cdot$ Biomarker

\section{INTRODUCTION}

Blood-based biomarkers can be used diagnostically as an aid to predict pregnancy outcome and direct mitigation strategies to negate pregnancy loss (Pavord \& Hunt 2018, Memtsa et al. 2019). In humans, the physiological demands of normal pregnancy inevitably result in alterations in both biochemical and hematological parameters as maternal

*Corresponding author: ashley.barratclough@nmmf.org adaptation and fetal development occurs (Chandra et al. 2012, Bazzano et al. 2014). Human fetal ultrasonographic evaluation can provide a more accurate assessment of fetal well-being and development; however, routine biochemistry and hematology can provide an additional indication of systemic maternal well-being (Gaccioli et al. 2017). Across all species, systemic maternal illness can impact fetal well-being and subsequently influence pregnancy

(C) The authors and, outside the USA, the US Government 2021. Open Access under Creative Commons by Attribution Licence. Use, distribution and reproduction are unrestricted. Authors and original publication must be credited.

Publisher: Inter-Research · www.int-res.com 
outcome (Kourtis et al. 2014). Early identification of inflammation, infection or metabolic derangements which could compromise pregnancy outcome are essential to allow appropriate treatment and maximize the chances of fetal survival (Brozos et al. 2011).

Limited information is known about bottlenose dolphin Tursiops truncatus conception and pregnancy success rates in both managed care and in their wild counterparts (Bergfelt et al. 2017). The definition of reproductive success varies from a live neonate to a live calf $1 \mathrm{yr}$ post-parturition, making comparison of reproductive success between wild and managed populations or different geographic regions challenging. Conversely, reproductive failure cannot be solely defined by lack of calf or neonatal loss, as this could exclude infertility or pre-term diagnoses of early embryonic loss and abortion. Longitudinal research has shown a high rate of neonatal survival in managed care, with success defined as $>30$ d neonate survival (Sweeney et al. 2010). Neonatal survival rates were as high as $78.2 \%$ from 1990-1999 and improved to $90.6 \%$ from $2000-2009$ in 3 institutions in the USA following the incorporation of novel intervention strategies (Sweeney et al. 2010). In wild dolphins, reproductive success may vary in relation to resource availability, environmental stress and population health. In wild dolphin populations, neonatal survival rates as high as $83 \%$ have been reported in Sarasota Bay, Florida, with success defined as pregnancy diagnosis confirmed with a live birth. A combined survival rate of $64.7 \%(22 / 34)$ has been documented among several southeastern US populations, with success defined as observing a calf up to $1 \mathrm{yr}$ post-pregnancy diagnosis (Wells et al. 2014, Kellar et al. 2017). However in the northern Gulf of Mexico, dolphins impacted by the Deepwater Horizon oil spill have reproductive success rates as low as $19.4 \%$ (7/36), with success defined as observing a calf up to 1 yr post-pregnancy diagnosis (Kellar et al. 2017). Identifying factors which could influence reproductive success is important in understanding demographic and population dynamics for conservation management of wild dolphin populations (Schwacke et al. 2017).

In humans and animals, including dolphins in managed care, close monitoring of maternal and fetal development via ultrasound can allow identification of reproductive abnormalities (Larsen et al. 1990, Ivančić et al. 2020, Saviano et al. 2020). Successive examinations that monitor reproductive development are more likely to identify anomalies than a single snapshot in time (Bucca 2006). Wild dolphin health assess- ments are usually limited to a single examination during pregnancy (Barratclough et al. 2019). Due to the seasonality of field work, exams are frequently conducted during the $1^{\text {st }}$ trimester, providing increased challenge to detect abnormalities; therefore, maximizing interpretation of biological data, such as biochemistry, hematology and ultrasound, is paramount to predicting pregnancy outcome.

In dolphins, physiological shifts in biochemical and hematological parameters are confirmed to occur during healthy gestation, with reference ranges for each trimester previously established (Barratclough et al. 2020). In this previous study from 1985-2017, there were 42 successful pregnancies from 20 different bottlenose dolphins at the US Navy Marine Mammal Program (MMP) which were used to establish normal reference ranges for each trimester. These dolphins were housed in the same environment and fed the same diet as the dolphins with failed pregnancy outcomes in this study, allowing direct comparison between the 2 cohorts. Several pregnancyrelated changes were observed to occur in dolphins which have not been reported in other mammals, such as the observation of hemoconcentration with increases occurring in hemoglobin (HGB) and hematocrit $(\mathrm{HCT})$ in the $3^{\text {rd }}$ trimester. Identifying speciesspecific alterations is important to prevent misdiagnosis of abnormalities. For example, increases in HCT in humans has been linked with reduced plasma volume expansion and is therefore a negative prognostic indicator of pregnancy outcome, whereas hemoconcentration is to be expected in dolphins (Scholl \& Reilly 2000, Barratclough et al. 2020).

Another interesting observation in successful dolphin pregnancies is the lack of iron decrease below normal levels throughout gestation (despite a significant drop between the $1^{\text {st }}$ and $3^{\text {rd }}$ trimesters). This is particularly interesting in cetaceans, as iron is a sensitive indicator of inflammation, and in many species iron supplementation is required during gestation (Milman et al. 2000, Nollens et al. 2018). Determining whether decreasing iron during gestation is still within normal ranges or whether it is a pathological decrease is important in the determination of whether iron supplementation is warranted (Taylor \& Lind 1976). Alkaline phosphatase (ALKP) is also a sensitive but non-specific marker of inflammation in cetaceans (Nollens et al. 2018). During normal gestation in dolphins, ALKP is documented to decrease; therefore, comparison with failed pregnancies is of great interest to assess the value in using ALKP as a biomarker of pregnancy outcome (Barratclough et al. 2020). 
One of the most important findings in evaluating the hemograms during successful pregnancy outcomes in dolphins is the stability of total white blood cell (WBC) count, which does not significantly increase or decrease across all 3 trimesters (Barratclough et al. 2020). A differential shift in lymphocytes and neutrophils between the $2^{\text {nd }}$ and $3^{\text {rd }}$ trimester is to be expected (lymphopenia likely due to downregulation of lymphopoiesis during pregnancy), however an absolute neutrophilia is not a normal finding (Barratclough et al. 2020). Established knowledge of a normal pregnancy hemogram enables optimizing treatment plans in managed care according to expected bloodwork changes. This study retrospectively analyzed alterations in blood samples from known failed dolphin pregnancies and compared them to previously reported reference intervals from successful pregnancies (Barratclough et al. 2020) to identify biomarkers associated with adverse pregnancy outcomes.

\section{MATERIALS AND METHODS}

Bottlenose dolphins included in the study were located at the US Navy MMP in open-ocean netted enclosures in San Diego Bay, California. Samples were collected from animals during their routine care and under the authorization of US Code, Title 10, USC 7524. MMP is accredited by the AAALAC and adheres to the national standards of the US Public Health Service Policy on the Humane Care and Use of Laboratory Animals and the Animal Welfare Act. Blood samples were obtained as part of routine diagnostic assessment of maternal health during pregnancy as part of the MMP's comprehensive preventative health program.

The MMP provides a varied diet according to fish species availability, primarily consisting of capelin Mallotus villosus, Atlantic croaker Micropogonias undulatus, herring Clupea harengus, mackerel Scomber japonicus, pinfish Lagodon rhomboides, squid Loligo opalescens and striped mullet Mugil cephalus. Each dolphin's calorific requirements were assessed individually, with dietary intake increasing throughout gestation to achieve approximately a $25 \%$ increase in caloric intake by the time of parturition, as previously described (Sweeney et al. 2010). Pregnant dolphins were also supplemented with oral hydration as clinically indicated, typically ranging from 1-3 1 of water per individual requirements \pm electrolyte supplementation per day. Retrospective cases from 19891996 received nutritional supplementation of Sea Tabs orally and, post 1996, dolphins received Mazuri ${ }^{\circledR}$ Vita-Zu Mammal 5M26 tablets.

Inclusion criteria for the retrospective analysis was confirmed failed reproductive outcome with multiple blood samples available throughout gestation. Failed pregnancy was defined as abortion (dead fetus expelled prior to $<352 \mathrm{~d}$ of gestation), perinatal loss (born > 352 d stillborn or weak, survived <24 h), stillbirth (dead fetus born after full term gestation) or failure to thrive (survived parturition and $>24 \mathrm{~h}$ but died within $30 \mathrm{~d}$ post-partum). A total of 21 failed pregnancies were included in the study with 263 blood samples obtained from 15 distinct dolphins throughout gestation, occurring between 1989 and 2017.

All blood samples utilized in this study were obtained using a 22 gauge butterfly needle and vacutainer collection system from the peripheral periarterial venous rete (PAVR) on the ventral fluke or using a 18 or 20 gauge 1.5 inch needle attached to a vacutainer collection system from the PAVR in the caudal peduncle. Blood was collected into BD vacutainers (BD) containing K-EDTA (potassium ethylenediaminetetra-acetic acid), sodium citrate and serum separator for analysis. Blood samples were shipped on ice packs to the Naval Medical Center San Diego clinical pathology laboratory for analysis or to Quest Diagnostic Laboratory. Comparability of the 2 laboratories was confirmed via prior science (Venn-Watson et al. 2007, 2013). Blood samples were assessed for standard biochemistry and hematology as reported in successful pregnancy outcomes (Barratclough et al. 2020). A total of 47 analytes were assessed; serum biochemistry analyses included total protein, albumin, total globulins, total albumin to total globulin ratio, glucose, blood urea nitrogen (BUN), creatinine, BUN to creatinine ratio (BUN:creat ratio), estimated glomerular filtration rate (eGFR), uric acid, total bilirubin, cholesterol, triglycerides, creatine kinase $(\mathrm{CPK}), \mathrm{ALKP}$, alanine aminotransferase (ALT), aspartate aminotransferase (AST), gamma-glutamyl transferase (GGT), lactate dehydrogenase (LDH) and serum electrolyte concentrations: sodium, potassium, chloride, calcium, phosphorus, magnesium, carbon dioxide $\left(\mathrm{CO}_{2}\right)$ and iron. Hematology analysis included CBC data: HGB, HCT/packed cell volume (PCV), red blood cell (RBC) count, mean corpuscular volume $(\mathrm{MCV})$, mean corpuscular hemoglobin $(\mathrm{MCH})$, mean corpuscular hemoglobin concentration (MCHC), red cell distribution width (RDW), platelets, mean platelet volume (MPV), erythrocyte sedimentation rate (SED60), WBC, absolute neutrophils, neutrophil \%, absolute monocytes, monocyte \%, absolute eosino- 
phils, eosinophil \%, absolute lymphocytes and lymphocytes \%. Endocrinological analysis included progesterone (P4).

Data analysis was performed using R v.3.5.2 (RStudio Team 2016, R Core Team 2018). Blood data were divided into trimesters with three $127 \mathrm{~d}$ intervals in full term gestation. In premature births or abortions, parturition start dates were determined using estimated age of fetus according to histopathology reports and/or fetal biparietal diameter on ultrasound examination. From each pregnancy, a single blood draw was randomly selected from each trimester, where available, using the 'dplyr' package in R (Wickham et al. 2018). Prevalence of analyte measurements outside the $95 \%$ reference intervals for successful pregnancy published by Barratclough et al. (2020) were calculated. The observed prevalence was compared to the expected $2.5 \%$ with binomial tests. Progesterone reference ranges were not previously published; however, normal references were calculated for the purposes of this study following the same methodology and using the same data set as previously described (Barratclough et al. 2020). Repeated measures (RM)-ANOVA was used to compare trimester results from failed pregnancy outcomes with Tukey's HSD post hoc tests to assess the differences among trimesters, with results considered significant at 0.05 . Prior to analysis, distribution of the residuals was assessed with Shapiro-Wilk tests and homogeneity of variance with Levene's tests. If necessary, data were Box-Cox transformed.

\section{RESULTS}

Twenty-one failed pregnancies were included in the study, with 263 blood samples obtained from 15 distinct dolphins throughout gestation, occurring between 1989 and 2017. Where available, a single blood sample was randomly selected from each trimester and included in the study. Variations in the number of samples available for each trimester resulted primarily from timing of reproductive failure and on occasion lack of maternal compliance for voluntary blood sampling. A single failure occurred in the $1^{\text {st }}$ trimester, 2 failures occurred in the $2^{\text {nd }}$ tri. mester, 8 in the $3^{\text {rd }}$ trimester, 8 neonates did not survive $>24 \mathrm{~h}$ and 2 neonates did not survive the first $30 \mathrm{~d}$. The 15 dams included in the study ranged in age from 11-41 yr at the time of the loss, with parity ranging from $1^{\text {st }}$ to $11^{\text {th }}$ pregnancy. Total dam length ranged from $232-278 \mathrm{~cm}$ and weight ranged from $139-291 \mathrm{~kg}$.

\subsection{Hematological and biochemical shifts among trimesters in failed pregnancies}

RM-ANOVA comparing trimester shifts during failed pregnancies showed hematological shifts in neutrophils with an increase in both \% and absolute count in the $3^{\text {rd }}$ trimester (Fig. 1). Lymphocyte \% showed a corresponding decline throughout gestation (Table S1 in the Supplement at www.int-res. com/articles/suppl/d144p197_supp.pdf). Eosinophils, $\%$ and absolute count, showed an increase in the $2^{\text {nd }}$ trimester followed by a significant decrease in the $3^{\text {rd }}$ trimester (Fig. 1). RBC distribution width \% showed a significant decrease in the $3^{\text {rd }}$ trimester (Fig. 2). Iron was significantly lower in the $3^{\text {rd }}$ trimester (Fig. 2).

Biochemical shifts between trimesters in failed cases included a decrease in calcium from the $2^{\text {nd }}$ to the $3^{\text {rd }}$ trimester (Fig. 3). ALKP (Fig. 3) was also significantly lower in the $3^{\text {rd }}$ trimester. ALT decreased in both the $2^{\text {nd }}$ and $3^{\text {rd }}$ trimesters. Cholesterol was observed to increase in the $3^{\text {rd }}$ trimester (Fig. 3).

Progesterone showed significantly lower levels in the $3^{\text {rd }}$ trimester in failures compared to the $1^{\text {st }}$ and $2^{\text {nd }}$ trimesters (Fig. 3). RM-ANOVA results for all analytes are included in Table S1.

\subsection{Comparison of blood profiles between pregnancies with successful and failed outcomes}

In comparing failed cases with successful reproductive outcome reference ranges, a high prevalence of several abnormalities was observed (Table 1), predominantly in the $2^{\text {nd }}$ and $3^{\text {rd }}$ trimesters. Hematological changes with significantly increased prevalence of abnormal analytes in failed pregnancies included elevated total WBC count in the $2^{\text {nd }}$ trimester and elevated absolute neutrophils in the $2^{\text {nd }}$ and $3^{\text {rd }}$ trimesters. In addition, elevated $2^{\text {nd }}$ trimester absolute monocytes were prevalent in failed pregnancies with decreased eosinophils \% occurring in the $3^{\text {rd }}$ trimester. A higher prevalence of low HCT, HGB and $\mathrm{RBC}$ values occurred in the $2^{\text {nd }}$ trimester in failed cases; low RBC and HCT were also prevalent in the $3^{\text {rd }}$ trimester. The increased prevalence of elevated SED60 occurred in the $2^{\text {nd }}$ trimester of failed reproductive outcomes.

Biochemical alterations observed in failed pregnancies compared to successful pregnancy reference ranges included elevated $\mathrm{CPK}$ in failed cases in the $3^{\text {rd }}$ trimester and an increased elevated estimated eGFR prevalence in the $2^{\text {nd }}$ trimester. Elevated globulins also showed higher prevalence in both $1^{\text {st }}$ and 

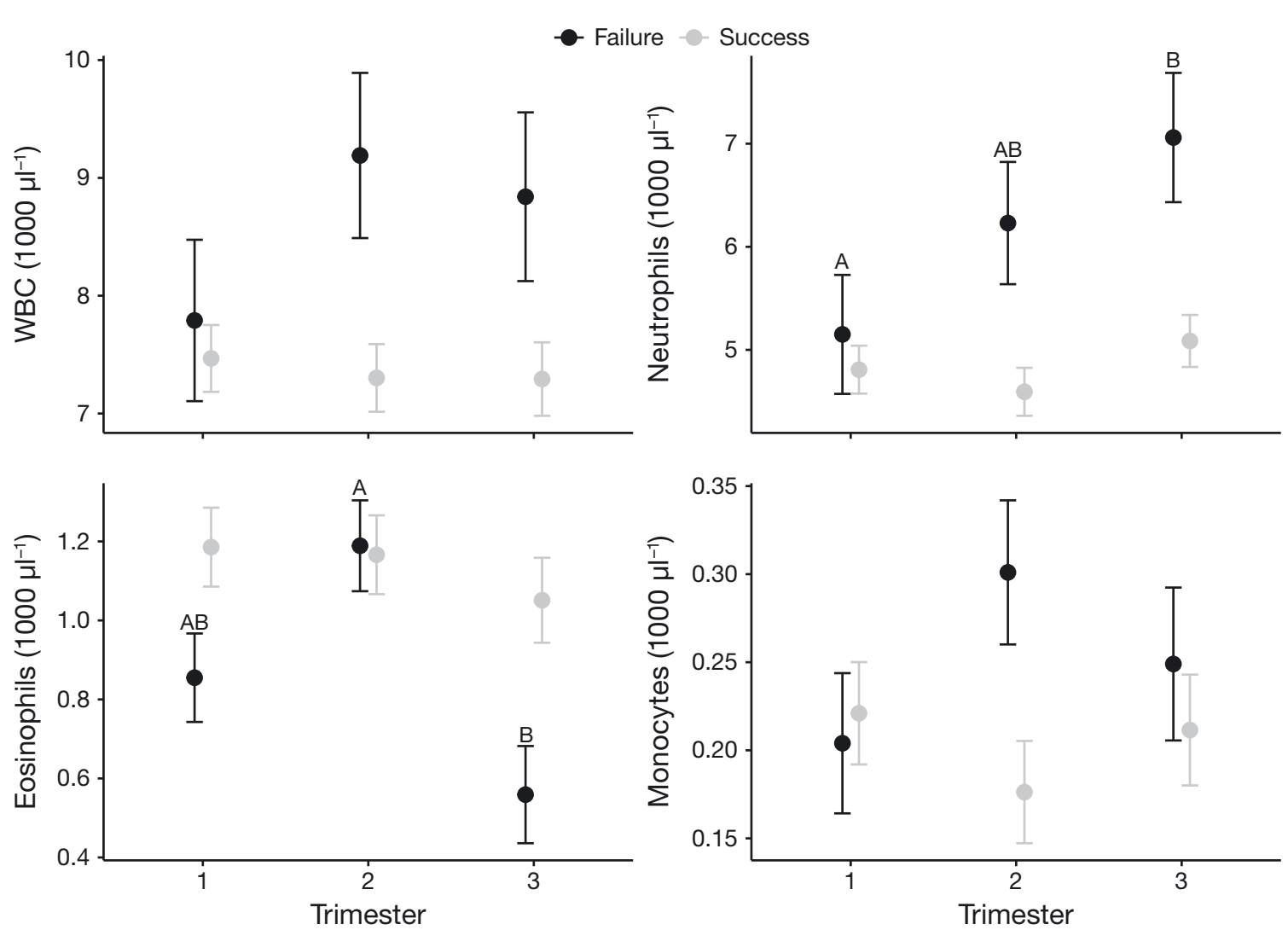

Fig. 1. Least square mean \pm SE from repeated measures $(R M)$-ANOVA. Where the RM-ANOVA $p<0.05$, different letters indicate Tukey's HSD $\mathrm{p}<0.05$. Least square mean \pm SE from RM-ANOVA of successful pregnancies presented in Barratclough et al. (2020) are plotted in grey as a reference. WBC: white blood cells

$2^{\text {nd }}$ trimester in failed pregnancies. There was a higher prevalence of low progesterone in the $3^{\text {rd }}$ trimester in failed cases compared to successful pregnancy reference ranges.

\section{DISCUSSION}

Maternal compromise via disease, nutrition or environmental contaminants can severely impact fetomaternal communications, critically affecting fetal well-being and, ultimately, reproductive outcome (Sibai et al. 1993, Wagner 2004). Disturbances in the feto-maternal placental exchange can manifest as maternal clinicopathological changes, potentially identifying subclinical changes via blood-based biomarkers. Fetal compromise can result in a failed reproductive outcome via abortion, stillbirth or neonatal death, all of which were included in this study (Bucca 2006). A compromised intrauterine environment can result from either maternal or fetal disorders. Changes primarily manifest in the form of either hypoxia, infection or an imbalance of in utero development (Levasseur 1983, Reef et al. 1995).
Blood-based biomarkers could be used for earlier identification of gestational abnormalities to facilitate an early diagnosis and treatment of any underlying maternal or fetal clinical conditions.

Retrospective evaluation of biochemistry and hematology results from known failed dolphin pregnancy outcomes has facilitated identification of blood-based biomarkers which could assist in predicting pregnancy outcome. Previously established successful gestation reference ranges in dolphins and expected physiological shifts has enabled identification of both aberrant biomarker levels and unusual shifts between trimesters, even if these significant changes remain within normal reference intervals (Barratclough et al. 2020). In fact, mean values from failed pregnancies in this study rarely fell outside of normal reference ranges for successful pregnancies. Biochemical and hematological abnormalities outside of specific gestational reference ranges - or, perhaps more importantly, abnormal aberrations between trimesters - can provide a pathophysiological indication of potential fetal loss (Poon \& Nicolaides 2014).

Due to the high reproductive success rate among dolphins in managed care, this longitudinal study 

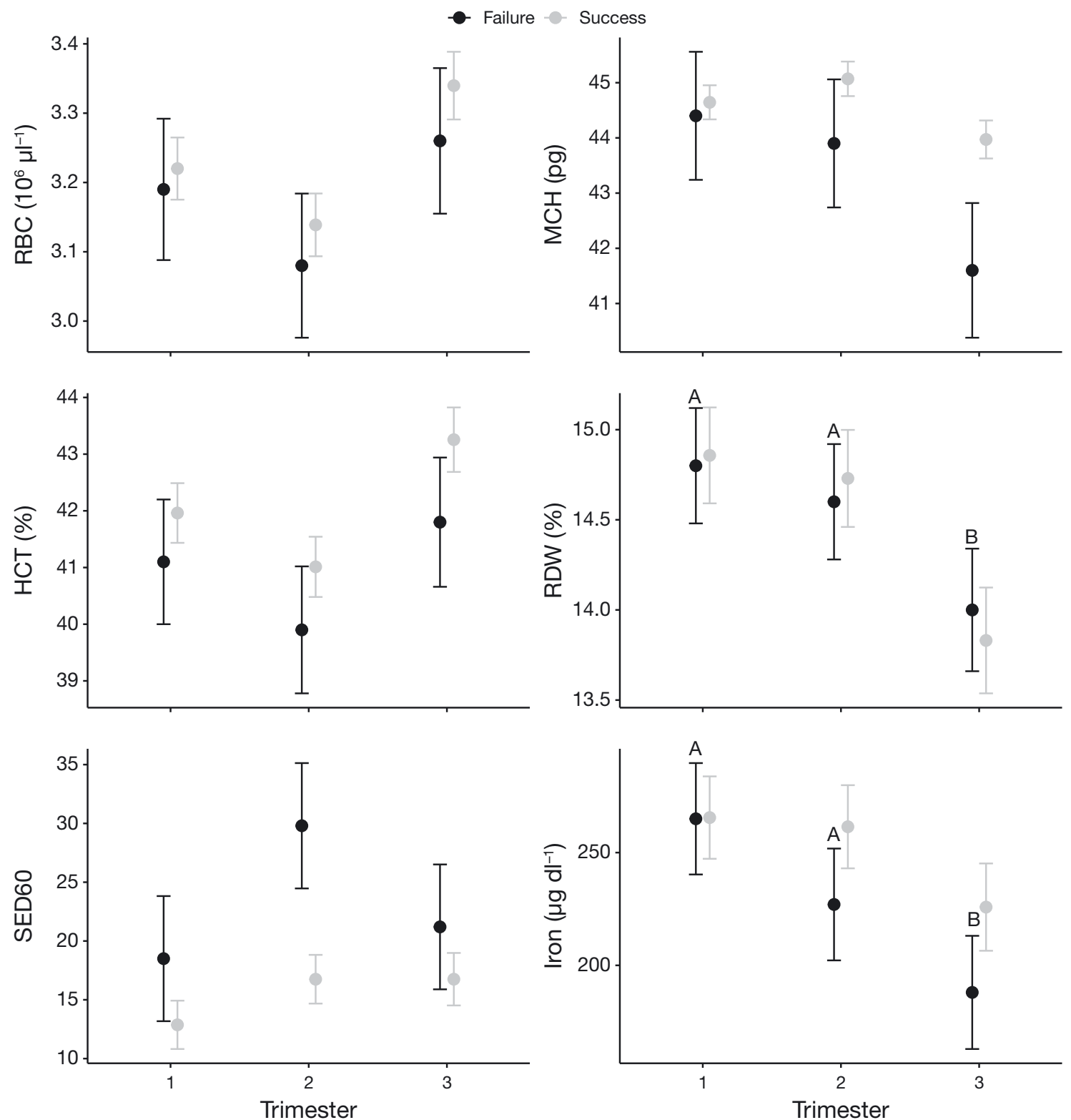

Fig. 2. Hematology results. Least square mean \pm SE from repeated measures (RM)-ANOVA. Where the RM-ANOVA $p<0.05$, different letters indicate Tukey's HSD $\mathrm{p}<0.05$. Least square mean \pm SE from repeated measures ANOVA of successful pregnancies presented in Barratclough et al. (2020) are plotted in grey as a reference. RBC: red blood cell; HCT: hematocrit;

SED60: erythrocyte sedimentation rate; $\mathrm{MCH}$ : mean corpuscular hemoglobin; RDW: red cell distribution width

required 28 yr to obtain sufficient cases for statistical analysis. Previous studies have shown similar results in the biochemical and hematology changes, but with smaller sample sizes preventing statistical analysis (Semenov et al. 2020). The most clinically relevant finding was significantly decreased progesterone values in failed pregnancies in the $3^{\text {rd }}$ trimester compared to successful pregnancies (Fig. 3, Table 1). This finding is in conjunction with other studies where fetal loss coincided with a decrease in circulating progesterone (O'Brien \& Robeck 2012). In dol- phins, the primary source of progesterone to support the fetus is the corpus luteum (CL) (Robeck et al. 2012). Clinically, if documenting low circulating progesterone via blood sample analysis, ultrasound examination of CL size and appearance is suggested. CL abnormalities causing a dramatic drop in progesterone could act as a predictor of fetal death, and indicate the likelihood of pregnancy termination (McDowell et al. 1988).

Multiple markers of low-grade maternal inflammation or infection, which could negatively impact the 

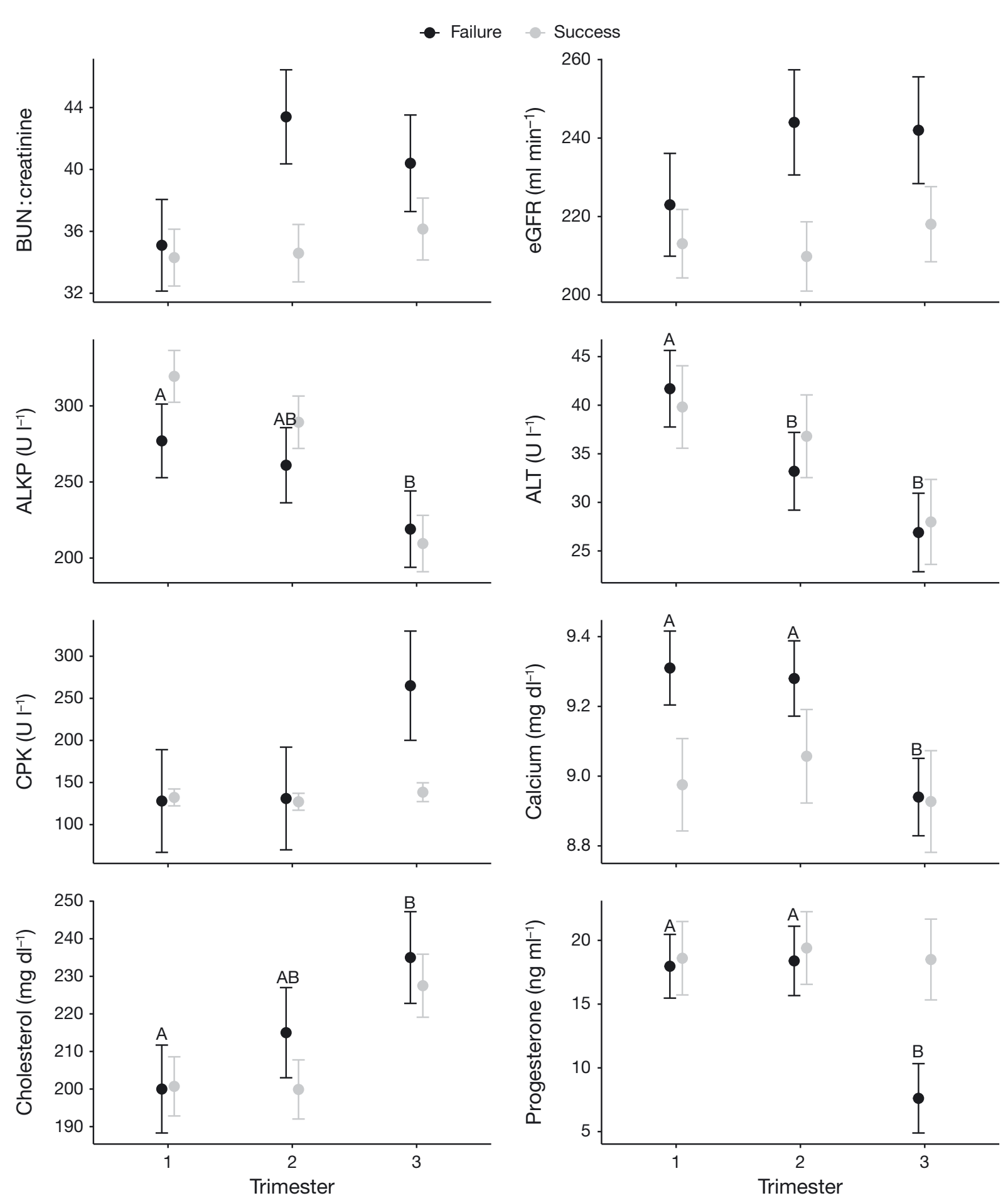

Fig. 3. Biochemistry and endocrinology results. Least square mean \pm SE from repeated measures (RM)-ANOVA. Where the RMANOVA $p<0.05$, different letters indicate Tukey's HSD $p<0.05$. Least square mean \pm SE from repeated measures ANOVA of successful pregnancies presented in Barratclough et al. (2020) are plotted in grey as a reference. BUN: blood urea nitrogen; ALKP: alkaline phosphatase; CPK: creatine kinase; eGFR: estimated glomerular filtration rate; ALT: alanine aminotransferase

pregnancy outcome, were present in failed pregnancy hematology and biochemistry results compared to successful pregnancies. These included raised total WBC count throughout gestation, increases in neutrophils, monocytes and SED60 in the $2^{\text {nd }}$ trimester as well as increases in CPK and decreases in ALKP in the $3^{\text {rd }}$ trimester (Figs. 1-3). Subtle changes in these analytes may not appear significant individ- 
Table 1. Prevalence and 95\% CIs of low or high values in failed pregnancies relative to reference intervals from successful pregnancies established in Barratclough et al. (2020). Binomial tests compared the observed prevalence in failed pregnancies to the expected $2.5 \%$ from successful pregnancies. WBC: white blood cell; RBC: red blood cell; HGB: hemoglobin; HCT: hematocrit; MCH: mean corpuscular hemoglobin; MPV: mean platelet volume; ALKP: alkaline phosphatase; CPK: creatine kinase; eGFR: estimated glomerular filtration rate. Bold font indicates a binomial test $\mathrm{p}<0.05$

\begin{tabular}{|c|c|c|c|c|c|c|c|}
\hline \multirow[t]{2}{*}{ Analyte } & & \multicolumn{2}{|c|}{$1^{\text {st }}$ trimester } & \multicolumn{2}{|c|}{$2^{\text {nd }}$ trimester } & \multicolumn{2}{|c|}{$3^{\text {rd }}$ trimester } \\
\hline & & Low & High & Low & High & Low & High \\
\hline WBC & Prevalence & 0.06 & 0.00 & 0.06 & 0.19 & 0.06 & 0.13 \\
\hline$\left(100 \mu \mathrm{l}^{-1}\right)$ & $95 \%$ CI & $0.002-0.302$ & $0-0.206$ & $0.002-0.302$ & $0.040-0.456$ & $0.002-0.302$ & $0.016-0.383$ \\
\hline $\mathrm{RBC}$ & Prevalence & 0.06 & 0.19 & 0.19 & 0.13 & 0.19 & 0.13 \\
\hline$\left(10^{6} 1^{-1}\right)$ & $95 \% \mathrm{CI}$ & $0.002-0.302$ & $0.040-0.456$ & $0.040-0.456$ & $0.016-0.383$ & $0.040-0.456$ & $0.016-0.383$ \\
\hline $\mathrm{HGB}$ & Prevalence & 0.06 & 0.13 & 0.25 & 0.13 & 0.13 & 0.06 \\
\hline$\left(\mathrm{g} \mathrm{dl}^{-1}\right)$ & $95 \%$ CI & $0.002-0.302$ & $0.016-0.383$ & $0.073-0.524$ & $0.016-0.383$ & $0.016-0.383$ & $0.002-0.302$ \\
\hline $\mathrm{HCT}$ & Prevalence & 0.06 & 0.06 & 0.19 & 0.13 & 0.19 & 0.00 \\
\hline$(\%)$ & $95 \%$ CI & $0.002-0.302$ & $0.002-0.302$ & $0.040-0.456$ & $0.016-0.383$ & $0.040-0.0456$ & $0-0.206$ \\
\hline $\mathrm{MCH}$ & Prevalence & 0.00 & 0.07 & 0.25 & 0.06 & 0.13 & 0.00 \\
\hline (pg) & $95 \%$ CI & $0-0.218$ & $0.002-0.319$ & $0.073-0.524$ & $0.002-0.302$ & $0.017-0.405$ & $0-0.218$ \\
\hline Platelets & Prevalence & 0.13 & 0.07 & 0.06 & 0.06 & 0.00 & 0.07 \\
\hline$\left(1000 \mu \mathrm{l}^{-1}\right)$ & $95 \%$ CI & $0.017-0.405$ & $0.002-0.319$ & $0.002-0.302$ & $0.002-0.302$ & $0-0.232$ & $0.002-0.339$ \\
\hline MPV & Prevalence & 0.14 & 0.07 & 0.00 & 0.13 & 0.00 & 0.00 \\
\hline (fl) & $95 \%$ CI & $0.018-0.428$ & $0.002-0.339$ & $0-0.218$ & $0.017-0.405$ & $0-0.265$ & $0-0.265$ \\
\hline Neutrophils & Prevalence & 0.00 & 0.00 & 0.00 & 0.19 & 0.00 & 0.40 \\
\hline$\left(1000 \mathrm{ul}^{-1}\right)$ & $95 \%$ CI & $0-0.206$ & $0-0.206$ & $0-0.206$ & $0.040-0.456$ & $0-0.218$ & $0.163-0.677$ \\
\hline Monocytes & Prevalence & 0.25 & 0.00 & 0.06 & 0.19 & 0.07 & 0.00 \\
\hline$\left(1000 \mu \mathrm{l}^{-1}\right)$ & $95 \%$ CI & $0.073-0.524$ & $0-0.206$ & $0.002-0.302$ & $0.40-0.456$ & $0.002-0.319$ & $0-0.218$ \\
\hline Eosinophils & Prevalence & 0.06 & 0.00 & 0.06 & 0.00 & 0.27 & 0.00 \\
\hline$(\%)$ & $95 \%$ CI & $0.002-0.302$ & $0-0.206$ & $0.002-0.302$ & $0-0.206$ & $0.78-0.551$ & $0-0.218$ \\
\hline Eosinophils & Prevalence & 0.06 & 0.00 & 0.06 & 0.00 & 0.13 & 0.00 \\
\hline$\left(1000 \mu \mathrm{l}^{-1}\right)$ & $95 \%$ CI & $0.002-0.302$ & $0-0.206$ & $0.002-0.302$ & $0-0.206$ & $0.014-0.405$ & $0-0.218$ \\
\hline Glucose & Prevalence & 0.06 & 0.00 & 0.00 & 0.00 & 0.00 & 0.25 \\
\hline$\left(\mathrm{mg} \mathrm{dl}^{-1}\right)$ & $95 \%$ CI & $0.002-0.302$ & $0-0.206$ & $0-0.206$ & $0-0.206$ & $0-0.206$ & $0.073-0.524$ \\
\hline Creatinine & Prevalence & 0.00 & 0.00 & 0.19 & 0.00 & 0.13 & 0.06 \\
\hline$\left(\mathrm{mg} \mathrm{dl}^{-1}\right)$ & $95 \%$ CI & $0-0.206$ & $0-0.206$ & $0.040-0.456$ & $0-0.206$ & $0.016-0.383$ & $0.002-0.302$ \\
\hline Uric acid & Prevalence & 0.27 & 0.00 & 0.13 & 0.00 & 0.25 & 0.06 \\
\hline$\left(\mathrm{mg} \mathrm{dl} \mathrm{l}^{-1}\right)$ & $95 \%$ CI & $0.078-0.551$ & $0-0.218$ & $0.016-0.383$ & $0-0.206$ & $0.073-0.524$ & $0.002-0.302$ \\
\hline Sodium & Prevalence & 0.06 & 0.00 & 0.00 & 0.06 & 0.00 & 0.19 \\
\hline$\left(\mathrm{mEq} \mathrm{l}^{-1}\right)$ & $95 \%$ CI & $0.002-0.302$ & $0-0.206$ & $0-0.206$ & $0.002-0.302$ & $0-0.206$ & $0.002-0.456$ \\
\hline Chloride & Prevalence & 0.19 & 0.00 & 0.00 & 0.00 & 0.06 & 0.19 \\
\hline$\left(\mathrm{mEq} \mathrm{l^{-1 }}\right)$ & $95 \%$ CI & $0.040-0.456$ & $0-0.206$ & $0-0.206$ & $0-0.206$ & $0.002-0.302$ & $0.040-0.456$ \\
\hline Protein & Prevalence & 0.00 & 0.19 & 0.00 & 0.13 & 0.06 & 0.06 \\
\hline$\left(\mathrm{g} \mathrm{dl}^{-1}\right)$ & $95 \%$ CI & $0-0.206$ & $0.40-0.456$ & $0-0.206$ & $0.016-0.383$ & $0.002-0.302$ & $0.002-0.302$ \\
\hline Globulins & Prevalence & 0.00 & 0.33 & 0.00 & 0.44 & 0.00 & 0.11 \\
\hline$\left(\mathrm{g} \mathrm{dl}^{-1}\right)$ & $95 \%$ CI & $0-0.336$ & $0.075-0.701$ & $0-0.336$ & $0.137-0.788$ & $0-0.336$ & $0.003-0.482$ \\
\hline Albumin: & Prevalence & 0.44 & 0.44 & 0.33 & 0.00 & 0.22 & 0.00 \\
\hline globulins & $95 \%$ CI & $0.137-0.788$ & $0.137-0.788$ & $0.075-0.701$ & $0-0.336$ & $0.028-0.600$ & $0-0.336$ \\
\hline Calcium & Prevalence & 0.00 & 0.00 & 0.00 & 0.25 & 0.06 & 0.13 \\
\hline$\left(\mathrm{mg} \mathrm{dl}^{-1}\right)$ & $95 \%$ CI & $0-0.206$ & $0-0.206$ & $0-0.206$ & $0.073-0.524$ & $0.002-0.302$ & $0.016-0.383$ \\
\hline Phosphate & Prevalence & 0.19 & 0.00 & 0.06 & 0.00 & 0.06 & 0.06 \\
\hline$\left(\mathrm{mg} \mathrm{dl}^{-1}\right)$ & $95 \%$ CI & $0.040-0.456$ & $0-0.206$ & $0.002-0.302$ & $0-0.206$ & $0.002-0.302$ & $0.002-0.302$ \\
\hline ALKP & Prevalence & 0.00 & 0.00 & 0.19 & 0.00 & 0.06 & 0.00 \\
\hline$\left(\mathrm{U} \mathrm{l}^{-1}\right)$ & $95 \%$ CI & $0-0.206$ & $0-0.206$ & $0.040-0.456$ & $0-0.206$ & $0.002-0.302$ & $0-0.206$ \\
\hline Bilirubin & Prevalence & 0.20 & 0.13 & 0.19 & 0.19 & 0.00 & 0.13 \\
\hline$\left(\mathrm{mg} \mathrm{dl}^{-1}\right)$ & $95 \%$ CI & $0.043-0.481$ & $0.17-0.405$ & $0.040-0.456$ & $0.040-0.456$ & $0-0.206$ & $0.016-0.383$ \\
\hline Iron & Prevalence & 0.00 & 0.00 & 0.06 & 0.00 & 0.25 & 0.06 \\
\hline$\left(\mu \mathrm{g} \mathrm{dl} \mathrm{l}^{-1}\right)$ & $95 \%$ CI & $0-0.218$ & $0-0.218$ & $0.002-0.302$ & $0-0.206$ & $0.073-0.524$ & $0.002-0.302$ \\
\hline CPK & Prevalence & 0.07 & 0.13 & 0.06 & 0.13 & 0.13 & 0.20 \\
\hline$\left(\mathrm{U} \mathrm{l}^{-1}\right)$ & $95 \%$ CI & $0.002-0.319$ & $0.017-0.405$ & $0.002-0.302$ & $0.016-0.383$ & $0.017-0.405$ & $0.043-0.481$ \\
\hline SED60 & Prevalence & 0.21 & 0.07 & 0.00 & 0.20 & 0.13 & 0.13 \\
\hline & $95 \%$ CI & $0.047-0.508$ & $0.002-0.339$ & $0-0.218$ & $0.043-0.481$ & $0.016-0.383$ & $0.016-0.383$ \\
\hline eGFR & Prevalence & 0.00 & 0.00 & 0.00 & 0.19 & 0.06 & 0.13 \\
\hline$(\mathrm{ml} \mathrm{min}-1)$ & $95 \%$ CI & $0-0.206$ & $0-0.206$ & $0-0.206$ & $0.040-0.456$ & $0.002-0.302$ & $0.016-0.383$ \\
\hline Progesterone & Prevalence & 0.08 & 0.08 & 0.09 & 0.00 & 0.33 & 0.00 \\
\hline$\left(\mathrm{ng} \mathrm{ml}^{-1}\right)$ & $95 \%$ CI & $0.002-0.360$ & $0.002-0.360$ & $0.002-0.413$ & $0-0.285$ & $0.099-0.651$ & $0-0.265$ \\
\hline
\end{tabular}


ually; however, the combined changes occurring in both hematology and biochemistry inflammatory biomarkers are likely predictors of a negative reproductive outcome.

In successful pregnancies, it is important to note that total WBC count was stable throughout gestation. In failed pregnancies, total WBC count was consistently higher throughout gestation than in successful pregnancies, primarily due to the increase in absolute count of neutrophils in the $2^{\text {nd }}$ and $3^{\text {rd }}$ trimesters (Fig. 1). Despite a significant increase in prevalence of elevated values in comparison to successful pregnancies, an absolute neutrophilia was not always observed, with values remaining within non-pregnant reference ranges $\left(4.43-13.53 \times 10^{3}{\left.\text { cells } \mathrm{l}^{-1}\right)}^{-}\right.$ (Barratclough et al. 2020). In order to accurately interpret the WBC differential for pregnancy health, it is essential to do so in the context of trimester and trend over time.

The prevalence of elevated monocytes in the $2^{\text {nd }}$ trimester was significantly higher in failed pregnancies, which is a similar finding to Canis familiaris bitches with failed pregnancies (Table 1). In dogs, a leukocytosis with a mild neutrophilia is expected in normal gestation; however, monocytosis is more indicative of abnormal inflammation (Davies \& Allen 1985, Kimberely et al. 2006). In this study, a true monocytosis was not observed; however, $2^{\text {nd }}$ trimester values were higher in failed pregnancies than in those with successful reproductive outcomes (Fig. 1).

Eosinophils showed a very interesting pattern in failed pregnancies, with an increase in the $2^{\text {nd }}$ trimester followed by a significant decrease in the $3^{\text {rd }}$ trimester, which was not observed in successful reproductive outcomes (Fig. 1). Non-pregnant reference ranges of eosinophils in dolphins may be normally as low as $1.3 \times 10^{3}$ cells $\mathrm{l}^{-1}$; therefore, eosinopenia can be difficult to document or diagnose. Monocyte and eosinophil results highlight the importance of assessing the differential shifts in the hemogram between trimesters in addition to the absolute values. Clinically, observing increasing trends in eosinophils, monocytes or neutrophils in the $2^{\text {nd }}$ trimester with a decrease in eosinophils in the $3^{\text {rd }}$ trimester should warrant increased observations during the pregnancy, as these shifts in blood biomarkers could all be indicative of poor reproductive outcome.

SED60 has historically been used as a marker of inflammation in cetaceans, and the prevalence of elevated values was significantly higher in the $2^{\text {nd }}$ trimester in failed pregnancies compared to successful reference ranges, supporting its use as a potential biomarker of pregnancy failure (Table 1) (Bossart et al. 2001, Manire et al. 2018). This could indicate abnormal maternal inflammation; therefore, additional diagnostics including ultrasonographic examinations would be warranted to identify the underlying cause. Where available, interpretation of D-dimer levels and fibrinogen levels in conjunction with SED60 could give a more accurate indication of underlying inflammation or coagulopathies (Barratclough et al. 2017).

In addition to hematological indicators of maternal inflammation, the prevalence of raised CPK was significantly higher in the $3^{\text {rd }}$ trimester in failed pregnancies, supporting the likelihood of maternal inflammation and muscle damage associated with an abnormal pregnancy (Table 1). A sharp decline in ALKP in cetaceans has been associated with inflammation and is a poor prognostic indicator, therefore plummeting levels during gestation (other than the expected gradual decrease throughout gestation) could be a negative prognostic indicator of fetal survival (Nollens et al. 2018). Abnormally low values of ALKP were more prevalent in the $2^{\text {nd }}$ trimester; however, significant decreases throughout gestation were only observed between the $1^{\text {st }}$ and $3^{\text {rd }}$ trimester levels in failed cases, mirroring the pattern observed in successful pregnancies (Table 1, Fig. 3) (Barratclough et al. 2020). The rate of ALKP decrease is likely more significant than actual values; therefore, where possible in managed care, longitudinal assessment is more valuable/informative than interpretation of a single value.

RBC had a significantly higher prevalence of abnormally low values in both $2^{\text {nd }}$ and $3^{\text {rd }}$ trimester in failed cases compared to successful reference intervals (Table 1 ). In addition, $\mathrm{MCH}$, which reflects the amount of HGB in each RBC, was found to have a significantly higher prevalence of low values in the $2^{\text {nd }}$ trimester in failed cases (Table 1 ). The prevalence of low HCT and HGB during the $2^{\text {nd }}$ trimester were also higher in failed pregnancies compared to successful reference intervals (Table 1). Overall, the trends in $\mathrm{RBC}, \mathrm{MCH}, \mathrm{HCT}$ and $\mathrm{HGB}$ observed throughout pregnancy were similar between failed and successful reproductive outcomes, although the failed pregnancies did not hemoconcentrate to the same degree (Fig. 2). Hemoconcentration in humans is associated with a significant increase in fetal death $(9 \times$ higher), but a degree of hemoconcentration in dolphin gestation is normal (Scholl \& Reilly 2000, Barratclough et al. 2020). In dolphins, it is likely of greater clinical significance if the HCT is decreasing during gestation rather than increasing (Fretts 2005). These observed shifts in $\mathrm{HCT}, \mathrm{HGB}, \mathrm{RBC}$ and $\mathrm{MCH}$ could be 
precursors for the development of anemia and therefore should be monitored closely as hemoconcentration is the expected change, not hemodilution or anemia. Additional diagnostics such as ultrasonographic evaluation of fetal health or urinalysis could be warranted to check hydration status.

Iron levels during failed pregnancies showed a gradual decrease that was significant between the $1^{\text {st }}$ and $3^{\text {rd }}$ trimester, mirroring the trend observed in successful pregnancies but to a greater degree (Fig. 2). Iron levels were observed to be lower in failed pregnancies compared to successful ones, with levels dropping below $<200 \mu \mathrm{g} \mathrm{dl}^{-1}$ in the $3^{\text {rd }}$ trimester (normal reference range for adult pregnant females in the $3^{\text {rd }}$ trimester: 100-479 $\mu \mathrm{g} \mathrm{dl}^{-1}$; Barratclough et al. 2020). Clinically, a reduction in iron throughout gestation should not be of great concern; however, if this is paired with other inflammatory markers such as a rapid decrease in ALKP or an increase in SED60 then additional diagnostics should be performed, such as a full maternal workup including fetal ultrasonography, to identify the cause of inflammation.

Increased eGFR had a higher prevalence of elevated values in the $2^{\text {nd }}$ trimester in failed pregnancies supported by an increase in BUN:Creat ratio in the $2^{\text {nd }}$ trimester compared to successful pregnancies (Fig. 3). This was a different pattern than the shifts observed in successful pregnancy where eGFR actually decreased in the $2^{\text {nd }}$ trimester (Fig. 3) to levels below the estimated eGFR in non-pregnant healthy dolphins (Venn-Watson et al. 2008, Barratclough et al. 2020). Further research is needed to understand the shifts in eGFR during dolphin gestation and how they are linked to reproductive outcome. It is possible that pre-renal azotemia was occurring in the failed cases, which has been observed in human cases (Nwoko et al. 2012). In most species, decreasing eGFR is of concern during gestation as this could indicate reduced excretion of fetal creatinine (Phippard et al. 1986, Jeyabalan \& Conrad 2007). In dolphins, however, an increase in eGFR in the $2^{\text {nd }}$ trimester (relative to the $1^{\text {st }}$ trimester) could be more likely to be associated with failed reproductive outcome. Increased eGFR could be contributing to the lack of hemoconcentration observed in failed cases, and the observed azotemia in the $2^{\text {nd }}$ trimester would warrant close maternal monitoring.

Calcium levels dropped significantly in the $3^{\text {rd }}$ trimester compared to the $1^{\text {st }}$ and $2^{\text {nd }}$ in failed pregnancies; however, levels did not drop below normal $3^{\text {rd }}$ trimester reference ranges (Fig. 3). It is important to note that this decrease in calcium was not observed in successful pregnancies, where calcium levels re- mained stable across all 3 trimesters. High calcium levels in the $2^{\text {nd }}$ trimester were more prevalent in failed pregnancies (Table 1), which provided the scope to decrease significantly in the $3^{\text {rd }}$ trimester. Therefore, elevated calcium levels during the $2^{\text {nd }}$ trimester may be a negative prognostic indicator and, even when levels are normal, a marked decrease in calcium during the $3^{\text {rd }}$ trimester is of concern. In other species such as ruminants, lean body condition is a precursor for pregnancy toxemia and hypocalcemia due to mobilization of calcium reserves for fetal skeletal mineralization and mobilization of calcium for lactation (Rook 2000, Brozos et al. 2011). Both the increased prevalence of elevated calcium in the $2^{\text {nd }}$ trimester and later marked decrease in the $3^{\text {rd }}$ trimester of failed dolphin pregnancies are significant findings in predicting failed reproductive outcome. Cholesterol should increase throughout gestation and, similarly to calcium, should be monitored in conjunction with body mass index assessment of the dam to ensure sufficient reserves to maintain a healthy pregnancy.

In wild dolphins, anticipating the expected biochemical or hematological changes can provide improved understanding of the state of pregnancy, facilitating outcome prediction. Wild dolphin health assessments involve a single physical examination during pregnancy, with photo-identification surveys monitoring the individual to determine pregnancy outcome (Lane et al. 2015, Barratclough et al. 2019). Due to the timing of health assessment examinations and minimal handling of late-stage females, the majority of wild dolphins are sampled during their $1^{\text {st }}$ trimester. Interpretation of hematological and biochemical abnormalities during gestation at a single time point is challenging, particularly in the $1^{\text {st }}$ trimester as discussed, with the majority of significant alterations associated with failure occurring the $2^{\text {nd }}$ and $3^{\text {rd }}$ trimesters. This study demonstrated that the shifts in biomarkers throughout the trimesters is potentially of greater clinical relevance than the absolute concentrations, making future application to a single wild sample challenging. This scientific study does, however, provide information on unexpected trimester shifts, with the to aim to elucidate the maximum information possible from a single snapshot in time from a pregnancy blood sample.

One of the limitations of this study was the potential influence of systemic medications such as antibiotics or antifungals, which could have influenced biochemical and hematological results; however, it is beyond the scope of this study to account for these possible effects. Dolphins included varied in age 
from 11-41 yr. All samples were classed as adults from a comparative standpoint, but it is possible that some biochemical changes occurring in the older animals could have been influenced by age. Previous studies have confirmed the increased likelihood of reproductive failure with increasing age (Karniski et al. 2018).

Predicting reproductive failure from biochemical and hematological bloodwork analysis is challenging due to the multiple aberrations possible from the different pathophysiological underlying causes of failure. This study identified potential blood-based biomarkers which could indicate maternal or fetal abnormalities, warranting closer patient monitoring and a targeted treatment approach or additional diagnostics such as maternal, placental and fetal ultrasound to monitor pregnancy development (Ivančić et al. 2020). Further research is needed to correlate specific pathophysiological causes of failure with sensitive blood-based biomarker shifts during failed pregnancy outcomes.

\section{CONCLUSIONS}

Clinically, the comparison of shifts in biochemical or hematological biomarkers over time is potentially of greater diagnostic value to a clinician than focusing on a single result. However, if circumstances arise where sequential monitoring is not an option, and only a single sample is available, the following analytes showed statistically significant prevalence changes. If repeated sampling is viable, significant shifts between trimesters and could be used as potential biomarkers of reproductive failure in bottlenose dolphins:

- Increased SED60 in the $2^{\text {nd }}$ trimester

- Low RBC, HCT and HGB in the $2^{\text {nd }}$ trimester

- $2^{\text {nd }}$ trimester increase in monocytes

- $2^{\text {nd }}$ or $3^{\text {rd }}$ trimester increase in neutrophils

- Increase in total WBC in the $2^{\text {nd }}$ trimester

- $3^{\text {rd }}$ trimester decrease in eosinophils

- Increased calcium in the $2^{\text {nd }}$ trimester or decreased calcium in the $3^{\text {rd }}$ trimester

- Decreasing progesterone in the $3^{\text {rd }}$ trimester

- Increased CPK in the $3^{\text {rd }}$ trimester

Acknowledgements. The authors thank the MMP government training staff and managers and the National Marine Mammal Foundation animal care specialists, veterinary and medical records staff who facilitated this study. This scientific study was made possible in part by a grant from The Gulf of Mexico Research Initiative. Data are publicly available through the Gulf of Mexico Research Initiative Information \& Data Cooperative (GRIIDC) at https://data. gulfresearchinitiative.org/data/R5.x274.000:0011. This is scientific contribution 292 of the National Marine Mammal Foundation.

\section{LITERATURE CITED}

Barratclough A, Ball RL, Floyd RF, Reep RL, Conner BJ (2017) Proposal and application of a novel disseminated intravascular coagulation scoring system in the Florida manatee (Trichechus manatus latirostris). J Zoo Wildl Med 48:152-158

*Barratclough A, Wells RS, Schwacke LH, Rowles TK and others (2019) Health assessments of common bottlenose dolphins (Tursiops truncatus): past, present, and potential conservation applications. Front Vet Sci 6:444

Barratclough A, Gomez FM, Morey JS, Deming A and others (2020) Pregnancy profiles in the common bottlenose dolphin (Tursiops truncatus): clinical biochemical and hematological variations during healthy gestation and a successful outcome. Theriogenology 142:92-103

Bazzano M, Giannetto C, Fazio F, Rizzo M, Giudice E, Piccione G (2014) Physiological adjustments of haematological profile during the last trimester of pregnancy and the early post partum period in mares. Anim Reprod Sci 149: 199-203

Bergfelt DR, Blum JL, Steinetz BG, Steinman KJ, O'Brien JK, Robeck TR (2017) Relaxin as a hormonal aid to evaluate pregnancy and pregnancy loss in bottlenose dolphins (Tursiops truncatus). Gen Comp Endocrinol 242:24-29

Bossart GDRT, Dierauf LA, Duffield DA (2001) Clinical pathology: hematology. In: Dierauf LA, Gulland FMD (eds) CRC handbook of marine mammal medicine, $2^{\text {nd }}$ edn. CRC Press, Boca Raton, FL, p 390-396

Brozos C, Mavrogianni VS, Fthenakis GC (2011) Treatment and control of peri-parturient metabolic diseases: pregnancy toxemia, hypocalcemia, hypomagnesemia. Vet Clin North Am Food Anim Pract 27:105-113

Bucca S (2006) Diagnosis of the compromised equine pregnancy. Vet Clin North Am Equine Pract 22:749-761

* Chandra S, Tripathi AK, Mishra S, Amzarul M, Vaish AK (2012) Physiological changes in hematological parameters during pregnancy. Indian J Hematol Blood Transfus 28:144-146

Davies JV, Allen WE (1985) Leucocytosis during normal pregnancy in a bitch. Vet Rec 116:412-413

Fretts RC (2005) Etiology and prevention of stillbirth. Am J Obstet Gynecol 193:1923-1935

Gaccioli F, Lager S, Sovio U, Charnock-Jones DS, Smith GCS (2017) The pregnancy outcome prediction (POP) study: investigating the relationship between serial prenatal ultrasonography, biomarkers, placental phenotype and adverse pregnancy outcomes. Placenta 59:S17-S25

* Ivančić M, Gomez FM, Musser WB, Barratclough A and others (2020) Ultrasonographic findings associated with normal pregnancy and fetal well-being in the bottlenose dolphin (Tursiops truncatus). Vet Radiol Ultrasound 61: 215-226

Jeyabalan A, Conrad KP (2007) Renal function during normal pregnancy and preeclampsia. Front Biosci 12:2425-2437

Karniski C, Krzyszczyk E, Mann J (2018) Senescence impacts reproduction and maternal investment in bottlenose dolphins. Proc R Soc B 285:20181123 
Kellar NM, Speakman TR, Smith CR, Lane SM and others (2017) Low reproductive success rates of common bottlenose dolphins Tursiops truncatus in the northern Gulf of Mexico following the Deepwater Horizon disaster (20102015). Endang Species Res 33:143-158

Kimberely ET, Casal ML, O'Donnell PA, Haskins ME (2006) Effects of pregnancy on complete blood cell counts and serum biochemical profiles in dogs. Theriogenology 66: 670

Kourtis AP, Read JS, Jamieson DJ (2014) Pregnancy and infection. N Engl J Med 370:2211-2218

Lane SM, Smith CR, Mitchell J, Balmer BC and others (2015) Reproductive outcome and survival of common bottlenose dolphins sampled in Barataria Bay, Louisiana, USA, following the Deepwater Horizon oil spill. Proc R Soc B 282:20151944

K Larsen T, Petersen S, Greisen G, Larsen JF (1990) Normal fetal growth evaluated by longitudinal ultrasound examinations. Early Hum Dev 24:37-45

Levasseur MC (1983) Utero-ovarian relationships in placental mammals: role of uterus and embryo in the regulation of progesterone secretion by the corpus luteum. A review. Reprod Nutr Dev 23:793-816

Manire CA, Reiber CM, Gaspar C, Rhinehart HL, Byrd L, Sweeney J, West KL (2018) Blood chemistry and hematology values in healthy and rehabilitated rough-toothed dolphins (Steno bredanensis). J Wildl Dis 54:1-13

McDowell KJ, Sharp DC, Grubaugh W, Thatcher WW, Wilcox CJ (1988) Restricted conceptus mobility results in failure of pregnancy maintenance in mares. Biol Reprod 39:340-348

Memtsa M, Jurkovic D, Jauniaux ERM (2019) Diagnostic biomarkers for predicting adverse early pregnancy outcomes. BJOG 126:e107-e113

Milman N, Byg KE, Agger AO (2000) Hemoglobin and erythrocyte indices during normal pregnancy and postpartum in 206 women with and without iron supplementation. Acta Obstet Gynecol Scand 79:89-98

Nollens HH, Venn-Watson S, Gili C, McBain JF (2018) Cetacean medicine. In: Gulland FMD, Dierauf LA, Whitman KL (eds) CRC handbook of marine mammal medicine, $3^{\text {rd }}$ edn. CRC Press, Boca Raton, FL, p 887-909

Nwoko R, Plecas D, Garovic VD (2012) Acute kidney injury in the pregnant patient. Clin Nephrol 78:478-486

* O'Brien JK, Robeck TR (2012) The relationship of maternal characteristics and circulating progesterone concentrations with reproductive outcome in the bottlenose dolphin (Tursiops truncatus) after artificial insemination, with and without ovulation induction, and natural breeding. Theriogenology 78:469-482

Pavord S, Hunt B (eds) (2018) The obstetric hematology manual. Cambridge University Press, Cambridge

Phippard AF, Horvath JS, Glynn EM, Garner MG, Fletcher PJ, Duggin GG, Tiller DJ (1986) Circulatory adaptation to pregnancy - serial studies of haemodynamics, blood volume, renin and aldosterone in the baboon (Papio hamadryas). J Hypertens 4:773-779

Poon LC, Nicolaides KH (2014) First-trimester maternal factors and biomarker screening for preeclampsia. Prenat Diagn 34:618-627

R Core Team (2018) R: a language and environment for statistical computing. R Foundation for Statistical Computing, Vienna

Reef VB, Vaala WE, Worth LT, Spencer PA, Hammett B (1995)
Ultrasonographic evaluation of the fetus and intrauterine environment in healthy mares during late gestation. Vet Radiol Ultrasound 36:533-541

Robeck TR, Gili C, Doescher BM, Sweeney J, De Laender P, Van Elk CE, O'Brien JK (2012) Altrenogest and progesterone therapy during pregnancy in bottlenose dolphins (Tursiops truncatus) with progesterone insufficiency. J Zoo Wildl Med 43:296-308

Rook JS (2000) Pregnancy toxemia of ewes, does, and beef cows. Vet Clin North Am Food Anim Pract 16:293-317

RStudio Team (2016) RStudio: integrated development for R. RStudio, Boston, MA

Saviano P, Fiorucci L, Grande F, Macrelli R, Troisi A, Polisca A, Orlandi R (2020) Pregnancy and fetal development: cephalic presentation and other descriptive ultrasonographic findings from clinically healthy bottlenose dolphins (Tursiops truncatus) under human care. Animals (Basel) 10:908

* Scholl TO, Reilly T (2000) Anemia, iron and pregnancy outcome. J Nutr 130:443S-447S

Schwacke LH, Thomas L, Wells RS, McFee WE and others (2017) Quantifying injury to common bottlenose dolphins from the Deepwater Horizon oil spill using an age-, sexand class-structured population model. Endang Species Res 33:265-279

Semenov VA, Rodin IA, Okolelova AI, Vinokurova DP, Gavrilov BV (2020) Control of fetal development in the female black sea bottlenose dolphin (Tursiops truncates Ponticus Barabash, 1940) using ultrasound procedure and studying the dynamics of the linear dimensions of the fetal head. Int J Manag Humanit 4:39-45

Sibai BM, Ramadan MK, Usta I, Salama M, Mercer BM, Friedman SA (1993) Maternal morbidity and mortality in 442 pregnancies with hemolysis, elevated liver enzymes, and low platelets (HELLP syndrome). Am J Obstet Gynecol 169:1000-1006

* Sweeney JC, Stone R, Campbell M, McBain J and others (2010) Comparative survivability of Tursiops neonates from three US institutions for the decades 1990-1999 and 2000-2009. Aquat Mamm 36:248-261

* Taylor DJ, Lind TJ (1976) Hematological changes during normal pregnancy: iron induced macrocytosis. $\mathrm{Br} \mathrm{J}$ Obstet Gynaecol 83:760-767

Venn-Watson S, Jensen ED, Ridgway SH (2007) Effects of age and sex on clinicopathologic reference ranges in a healthy managed Atlantic bottlenose dolphin population. J Am Vet Med Assoc 231:596-601

*Venn-Watson S, Smith CR, Dold C, Ridgway SH (2008) Use of a serum-based glomerular filtration rate prediction equation to assess renal function by age, sex, fasting, and health status in bottlenose dolphins (Tursiops truncatus). Mar Mamm Sci 24:71-80

*Venn-Watson S, Smith CR, Stevenson S, Parry C and others (2013) Blood-based indicators of insulin resistance and metabolic syndrome in bottlenose dolphins (Tursiops truncatus). Front Endocrinol 4:136

WWagner LK (2004) Diagnosis and management of preeclampsia. Am Fam Physician 70:2317-2324

Wells RS, Smith CR, Sweeney JC, Townsend FI and others (2014) Fetal survival of common bottlenose dolphins (Tursiops truncatus) in Sarasota Bay, Florida. Aquat Mamm 40:252-259

Wickham H, Francois R, Henry L, Müller K (2018) dplyr: a grammar of data manipulation. R package version 0.7.6. https://dplyr.tidyverse.org 